\title{
Der Weg der Drucklettern
}

Erhard Taverna

\section{Hundert Jahre nach Gutenberg kommen in Rom und Florenz arabische, syrische und persische Schriften aus der Druckerpresse.}

und Mathematiker im Exil. Mit Hilfe eines MediciKardinals mit besten Bankverbindungen in der damaligen Finanzmetropole Florenz druckte der Verlag bis 1588 im Auftrag des Vatikans religiöse Schriften, darunter ein arabisch-lateinisches Evangelium in einer Auflage von 3500 Exemplaren.
Über dem Kreuzgang der Basilika von San Lorenzo schuf Michelangelo die europaweit erste Bibliothek, die ab 1571 öffentlich zugänglich war. Wer über die dreifach geschwungene Treppe den prächtigen Lesesaal durchquert, gelangt zu einer Ausstellung der Biblioteca Medicea Laurenziana, die mit einer faszinierenden Ausstellung «Le vie delle lettere - la Tipografia Medicea tra Roma e l'Oriente» an ein beinahe vergessenes Gebiet der Gutenberg-Galaxis erinnert. Handgeschriebene Manuskripte und gedruckte Bücher der Medizin, Astronomie, Geometrie und Grammatik liegen ausgebreitet in Glasvitrinen, interaktive Bildschirme, Filme und Kommentare (italienisch und englisch) eröffnen den Zugang zu einem einzigartigen Kapitel der Renaissance. Die treibende Kraft war Raimundi, der auf seine Kosten Emissäre aussandte, die den ganzen Nahen Osten als Forscher, Händler und Einkäufer wertvoller Schriften durchreisten. Die Wege führten über Tripolis, Alexandrien nach Aleppo, Damaskus und Bagdad bis nach Goa. Abhandlungen zu Euklids Elementen, Abschriften des Kanons von Avicenna und seinen Schülern, Landkarten, astronomische Tafeln, geographische und geologische Berichte wurden nach Florenz gebracht, überarbeitet, ergänzt und für den Export nachgedruckt. Grammatik- und Wörterbücher mussten erst geschaffen werden, denn der Verleger unterrichtete orientalische Sprachen. Er über-

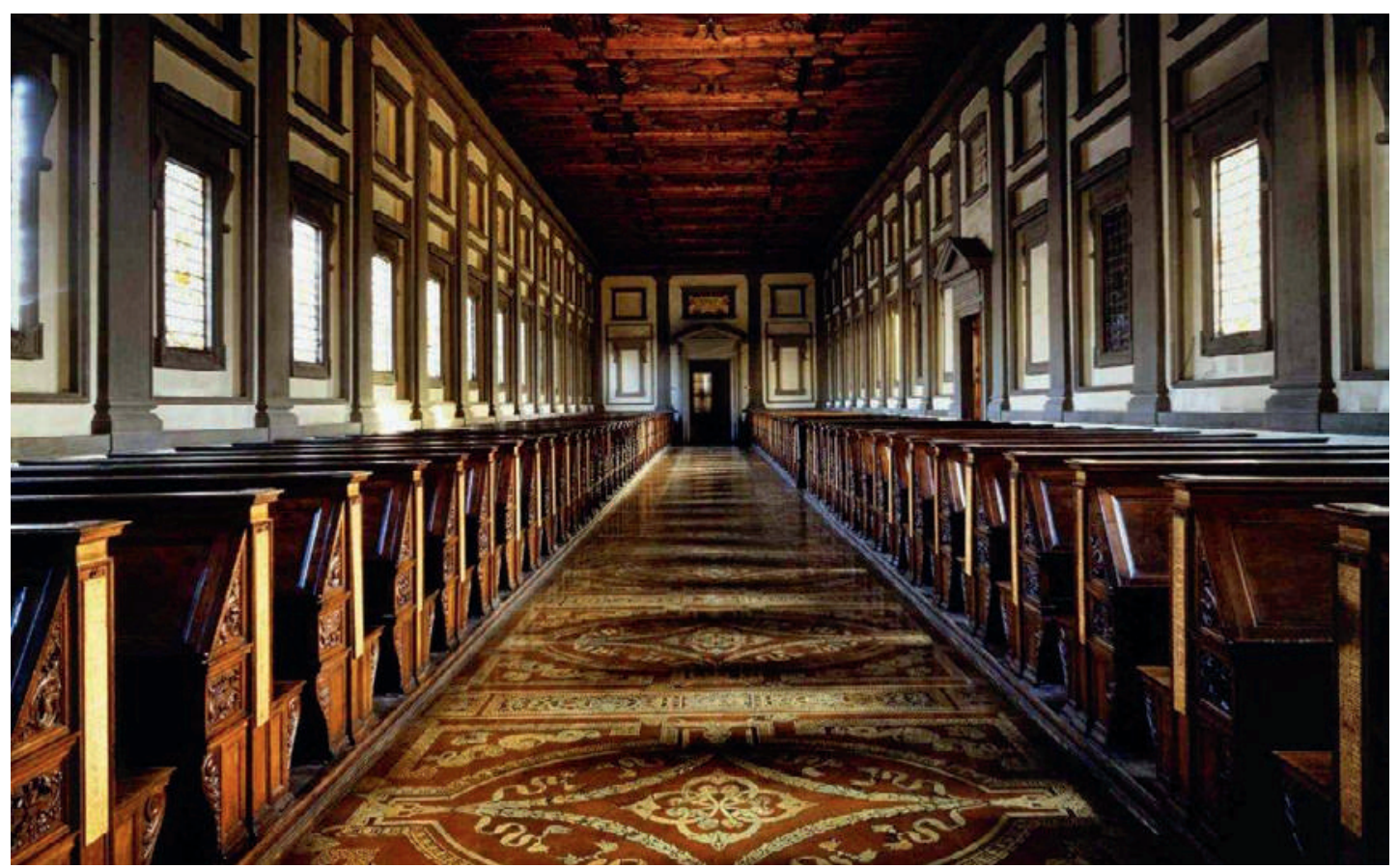

Lesesaal der Biblioteca Medicea Laurenziana in Florenz, entworfen von Michelangelo Buonarotti. Der Gang zwischen den Lesebänken ist ausgestattet mit kostbaren Steinmosaiken. 
wachte den Guss der Drucklettern, organisierte Arbeitsabläufe und Finanzen, verhandelte mit dem Klerus und potentiellen Kunden. Es gab vor und nach ihm andere Druckwerkstätten in Italien, Frankreich, Deutschland, Holland und England, doch keine Werkstatt erreichte seine verlegerische Breite, ästhetische Präzision und Effizienz. Eine Druckerpresse und bestens erhaltene Lettern, mit einer eigenen, langen Geschichte, gehören zu den zahlreichen Exponaten. Von 1514 bis Ende 18. Jahrhundert wurden in Europa über 250 Titel in arabischer Sprache gedruckt. Doch finanziell war das ambitiöse Unternehmen kein Erfolg. Auch die missionarische Absicht blieb fruchtlos, ebenso wie die Bemühungen, maronitische und weitere Ableger wieder der katholischen Kirche zuzuführen. Als einziger, relativer Bestseller erwies sich Avicennas «Libri quinque canonis medicinae» von 1593 ,

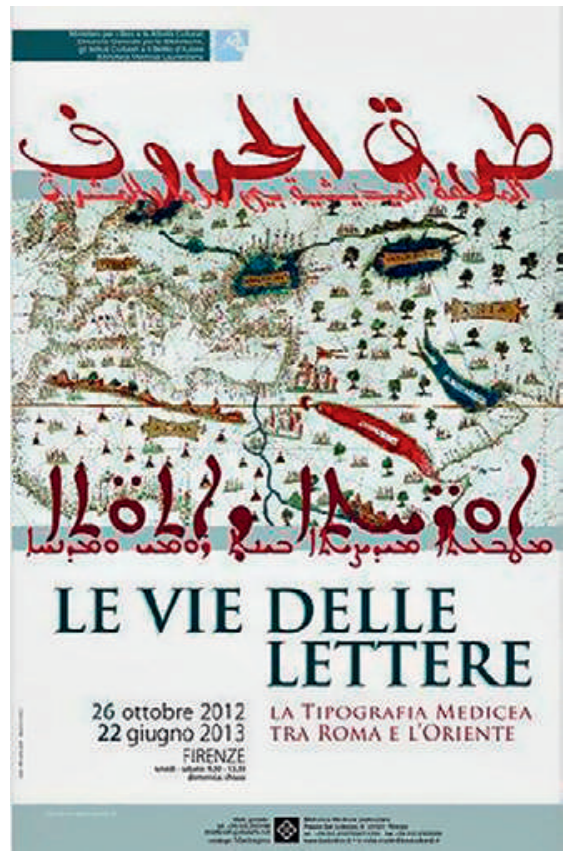

fernzuhalten. Die meisten Verlagswerke wurden an Geistliche und Diplomaten verschenkt oder zu Schulungszwecken verwendet. Kulturell war das humanistische Experiment zumindest für Europa ein Erfolg, denn nach den griechischen und hebräischen Texten fanden auch die arabischen Errungenschaften Aufnahme in den massgebenden intellektuellen Kreisen. Und nicht zuletzt trugen die Skripte und Kenntnisse des Patriarchen Na'matallah zur erfolgreichen Einführung des Gregorianischen Kalenders von 1582 bei.

Einzelne Objekte stammen aus der Privatsammlung «Green Collection» in Oklahoma City. Aus dieser Zusammenarbeit ist den Kuratorinnen eine hervorragende Ausstellung gelungen, die durch einen ausführlichen und schön illustrierten Katalog (nur in italienischer Sprache) ergänzt wird. Mit einer jährlichen Ausstellung macht die von dem einzelne Exemplare, gemäss Augenzeugen, noch im 20. Jahrhundert Verwendung fanden. Mit einer einmaligen Ausnahme verboten alle osmanischen Sultane die Verbreitung gedruckter Bücher. Nur den christlichen Minderheiten wurden religiöse Texte aus Rom zugestanden. Zu gross blieb das Misstrauen gegenüber den Bekehrungsversuchen aus Rom, und zudem verstand es die Kopistenzunft am Hof der Pforte, erfolgreich die Konkurrenz des modernen Buchdrucks 250 Jahre vom Reichsgebiet
Biblioteca Medicea Laurenziana von sich reden. Selten ist eine Geschichtslektion so eindrucksvoll und unterhaltend zu haben.

\section{Le vie delle lettere -}

la Tipografia Medicea tra Roma e l'Oriente Ausstellung in der Biblioteca Medicea Laurenziana der Basilika von San Lorenzo, Florenz. Bis 22. Juni 2013. 